\title{
Performance Evaluation of A Developed Dewatered Cassava Mash Sifter
}

\author{
Akinfoye O. D. Adejumo* \\ Department of Agricultural and Bio-Environmental Engineering Federal College of Agriculture, Moor \\ Plantation, P.M.B. 5029, Ibadan \\ Titus A .Ilori \\ Department of Agricultural and Bio-Environmental Engineering \\ Federal College of Agriculture, Moor Plantation, P.M.B. 5029, Ibadan \\ Bukola O. Afolabi \\ Department of Agricultural and Bio-Environmental Engineering \\ Federal College of Agriculture, Moor Plantation, P.M.B. 5029, Ibadan \\ M. Adegbie \\ Department of Agricultural Engineering, Federal College of Animal Health and Production, Ibadan.
}

\section{The research is Self-financed}

\section{Abstract}

A cassava pulp sifter for grated and dewatered cassava was developed and evaluated. The machine was evaluated at three operating speeds of 260rpm, 350rpm and 530rpm and masses of $1 \mathrm{~kg}, 2 \mathrm{~kg}$ and $3 \mathrm{~kg}$. It was observed that increase in the speed of operation increased both sieving capacity and sieving efficiency of the machine. Increase in mass, increased sieving capacity and decreased sieving efficiency. The average maximum sifting efficiency and capacity were $95.32 \%$ and $613.16 \mathrm{~kg} / \mathrm{hr}$ respectively. All the materials used for the fabrication were obtained locally and the machine has low labour requirements which can be adopted in gari processing industries.

Keywords: Cassava, Dewatered, Mash, Performance Evaluation, Shifter

DOI: $10.7176 / F S Q M / 99-04$

Publication date:July $31^{\text {st }} 2020$

\section{Introduction}

Farmers in Africa have long recognized the values of cassava as an insurance crop against famine and food shortages. Cassava is generally thought of as a poor man's food. Commercial demand for it is often dropped when cheap imports of wheat, rice and maize have been made available. Although, cassava is an excellence source of carbohydrate, it also has negligible protein content and most of its vitamins and minerals are either washed or cooked away during processing. There are over 1,000 local cassava verities especially in West Africa, better and sweet variation been the major types. Cassava is an important source of energy to man and animals. It is easy to propagate and also has ability to tolerate drought and yet maintain yield. Cassava can be processed into varieties of food for man among which are gari, Fufu/akpu, starch, abacha, tapioca, kpokcogari and Lafun (cassava flower) among the rural dwellers (IITA,2005).

Gari is a granulated white or yellowish product depending on production methods, having a high swelling capacity and can absorb up to 4times its volume in water. It has 10 to $15 \%$ moisture content that enhance good storability (Adejumo and Ola,2010). There is high demand for cassava products both locally and abroad. In Nigeria, there is a Federal Government directive that producer of flowers for baking must include 10\% cassava in their products. The Chinese and other Asia countries have also ordered for large quantities of cassava chips. There is no doubt therefore that the cost of gari the most popular food derived from cassava will increase. One solution to the impending scarcity of gari is the development of small-scale technologies for increase in gari production (Agbetoye and Oyedele, 2007).

Sifting of cassava mash is an important aspect in processing of cassava. It is done before frying to ensure that particles have uniform size. The uniformity in the size will ensure uniform roasting during garification. The final product as well must be uniform in size as to attract good market value (Adejumo and Ola 2010). Traditional method of sifting is still adopted by most gari processing industries in Nigeria, probably due to its less hazardous and stressfulness compared to some other gari processing operations like peeling, grating and frying. However, there exist the problems of rubbing fingers and Pam against the sieve (palm fibre or wire mesh) which can cause injury to the operator's hand, drudgery can result in mass production for commercial purpose, ergonomics effect on the operator and timelines of operation.

According to Agbetoye and Oyedele (2007), Igoni (2000) constructed a continuous flow rotary sieve for dewatered cassava mash. It sieved gari at moisture content of $47.6 \%$ with sieving efficiency of $48.6 \%$, recommended 
to be low. Also Jimoh and Oladipo (2000), developed similar gari sifter which consisted of reciprocating screen and powered electrically with $1.2 \mathrm{kw}$ electric motor, had sieving capacity of $8.0 \mathrm{~kg} / \mathrm{h}$ and sieving efficiency of $61 \%$.

Agbetoye and Oyedele (2007) developed a dual powered gari sifter and obtained maximum sifting capacity of $84 \mathrm{~kg} / \mathrm{h}$ and sifting efficiency of $97.3 \%$ of grated and de-watered gari mash. The machines was operated manually and powered by electric motor at machine speed of 266rpm, 355rpm, 533rpm and had sifting capacity and sifting efficiency increased to $170 \mathrm{~kg} / \mathrm{h}$ and $98 \%$ respectively. Increase in speed increased both sifting capacity and efficiency. Adejumo and Ola (2010), developed a combine gari post grinder shifting machine and observed that the machine shifting efficiency decreases with increase in loading of the machine while the grinding efficiency increased. The highest sifting capacity, sifting efficiency, grinding efficiency and gari grains loss were $28.2 \mathrm{~kg}$, $85.5 \%, 84.0 \%$ and $27.3 \%$ respectively. Jackson et al (2011), observed that operating speed of a motorized dewatered cassava mesh had a significant effect on the shifting efficiency and got the highest sifting efficiency of $86.57 \%$ at machine spread of 650rpm. Samaila et al. (2010) developed and evaluated a motorized cassava sifter and obtained highest sifting efficiency of $90 \%$ at sifting speed of 450rpm with an output capacity of $132.78 \mathrm{~kg} / \mathrm{h}$. The machine output capacity increased with speed from 340 to $450 \mathrm{rpm}$ and decreased thereafter to $500 \mathrm{rpm}$.

Sieving of gari is one of the major problems in Gari processing over the year that demand solution. A motorized cassava pulp sieve machine offering mechanical construction using indigenous technology and locally sourced materials assistance to achieving a desired result is highly essential in order to bypass the traditional method of sieving having numerous challenges associated with it. The machine will reduce the stress that Gari producers normally pass through during the processing and therefore enhance the quality of its production in our society. Hence, the objectives of this work are to developed and evaluate a gari sifter that will reduce the stress and time associated in Gari sieving operation.

\section{Materials and Methods}

\subsection{Construction}

The design and construction of the Gari sifting machine was carried out in the Agricultural Engineering Department Workshop, Federal College of Agriculture, Ibadan. Locally sourced materials were cut, welded, butted according to the design specifications. The machine is as shown on plate 1 . The major components of the machine are frame, sieving unit and the power wait. The frame is made-up of angle iron of $2.5 \mathrm{~mm}$ thickness. The sieving unit consist of a metal base of $20 \times 20 \mathrm{~mm}$ angle iron of $600 \times 900 \mathrm{~mm}$ rectangular shaped and a rectangular wooden frame $600 \times 900 \mathrm{~mm}$ with metal sieve attached to the base which serves as the hopper and gari outlet made of galvanized sheet to avert gari contamination. The sieve hopper is an open wooden box as to allow easy loading of gari, and connected to the power unit via a link and cam on a shaft of $19 \mathrm{~mm}$ diameter and $200 \mathrm{~mm}$ long. A pulley on shaft is connected to ic engine or electric motor with a v-belt for power transmission. The pulley on the shaft can be replaced with a crank and handle for manually powered operation.

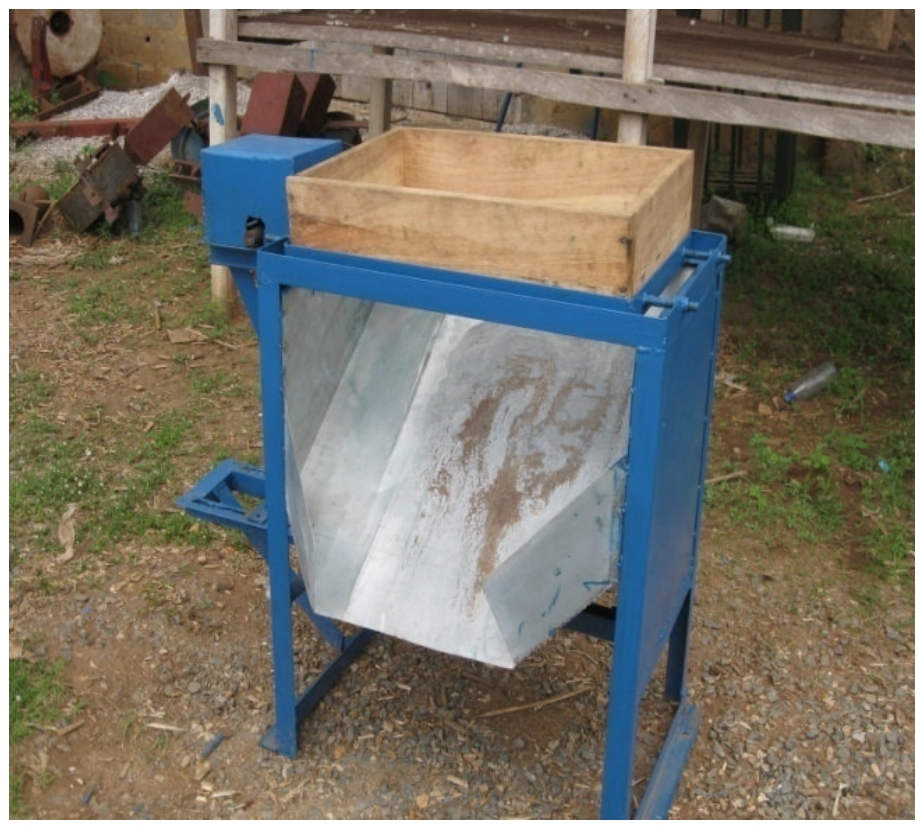

Plate 1: Cassava Sifting Machine 


\subsection{Operation of the machine}

The gari shifter is powered by $2 \mathrm{hp}$ electric motor or ic engine and can be powered manually where electricity or fuel for ic engine are not available by the use of crank and handle. The power is transmitted from the motor via belt and pulley arrangement to the power shaft carrying a cam which transmits the rotary motion to reciprocation of the sieve. Gari mash on the sieve is shake and the grains smaller than the screen size falls by force of gravity on the gari outlet which is at $45^{\circ}$ below the sieve for easy discharge into collecting trough. The wooden box is easily pull of the base and the chaff discharged; then replace for the continuation of the batch process.

\subsection{Machine Evaluation}

Bulk sample of dewatered cassava mash was collected from gari processing unit of the College farm. The lumpy were broken and the sample thoroughly mixed together, then a known mass are carefully manually sieved to determine the ratio of cassava mash to chaff in the bulk. The samples were carefully manually sieved and ratio calculated, replicated three times.

The machine was evaluated at various loading of $1 \mathrm{~kg}, 2 \mathrm{~kg}$ and $3 \mathrm{~kg}$; machine speed of 260rpm, 350rpm and $530 \mathrm{rpm}$ achieved by the use of a step turned pulley on an electric motor, and speeds confirmed with the use a tachometer.

Gari mesh sample was poured into the sieving unit and properly spread out. The machine was operated until the gari was completely sieved. The time taken was noted and recorded. The well sieved gari and chaff were weighed and recorded. The machine sieved chaff was carefully sieve manually and the weight of well sieved recorded. The procedure was replicated three times following the experimental design of $3 \times 3 \times 3$ complete block design (CBD).

The machine performance was calculated using the following criteria.

$$
S c=\frac{m}{t}
$$

Where,

$\mathrm{Sc}=$ Sifting capacity $(\mathrm{kg} / \mathrm{hr})$

$\mathrm{M}=$ Mass of cassava pulp loaded into the sieving unit

$\mathrm{t}=$ time taken for the sifting to be completed.

$$
S e=\frac{M c}{M c+M n} X \frac{100}{1}
$$

Where,

$\mathrm{Se}=$ sifting efficiency $(\%)$

$\mathrm{Mc}=$ Mass of machine sieved cassava mash

$\mathrm{Mn}=$ Mass of manually sieved cassava mash

The data collected were analysied statistically using ANOVA and mean separated using Duncan Multiple Range Test (DMRT).

\section{Results and Discussion}

The analyzed machine performance data of the study carried out are as presented in Table 1 to 3.

\begin{tabular}{|c|c|c|c|c|c|c|c|}
\hline & \multirow{2}{*}{$\begin{array}{l}\text { Speed(rpm) } \\
260\end{array}$} & \multicolumn{2}{|c|}{$\begin{array}{l}1 \mathrm{~kg} \\
\text { Rep.1 Rep2 }\end{array}$} & \multicolumn{2}{|c|}{$\begin{array}{l}\text { 2kg } \\
\text { Rep.1 Rep2 }\end{array}$} & \multicolumn{2}{|c|}{$\begin{array}{l}\text { 3kg } \\
\text { Rep.1 Rep2 }\end{array}$} \\
\hline & & 212.26 & 238.41 & 224.37 & 273.23 & 314.50 & 335.93 \\
\hline \multirow{2}{*}{ Capacity Kg/hr } & 350 & 340.91 & 246.04 & 601.00 & 685.71 & 804.60 & 894.78 \\
\hline & 530 & 551.30 & 679.25 & 560.31 & 690.32 & 562.50 & 635.29 \\
\hline \multirow[t]{3}{*}{ Efficiency \% } & 260 & 93.18 & 96.59 & 98.98 & 99.82 & 89.63 & 93.70 \\
\hline & 350 & 98.99 & 94.32 & 85.39 & 98.81 & 81.48 & 84.07 \\
\hline & 530 & 85.23 & 88.64 & 89.89 & 99.18 & 88.89 & 94.81 \\
\hline
\end{tabular}

Table 1: Gari Sifter Performances

From Table 1, the maximum mean sifting capacity and sifting efficiency are $613.16 \mathrm{~kg} / \mathrm{hr}$ and $96.32 \%$ respectively. It is observed that sifting capacity increased with increase in machine speed but decreased sifting efficiency. Also sifting capacity increased with increase in mass of dewatered cassava pulp while sifting efficiency increased to optimum at $2 \mathrm{~kg}$ per batch and decreased thereafter. The analysis of variance showed that speed has no significant effect $(\mathrm{P}<0.05)$ on the sifting capacity and sifting efficiency, but mass is highly significance on sifting capacity and efficiency. The mean maximum sifting efficiency (95.35\%) was found to be higher the $61 \%$ of Jimoh and Oladipo (2000) and 85.5\% of Adejumo and Ola (2010). Also, the maximum sifting efficiency $99.18 \%$ was higher than that of Agbetoye and Oyedele (2007), of 97.3\% and Samaila et al. (2010), of 90\%. 
Table 2: Effect of speed and mass on sieving capacity and efficiency

\begin{tabular}{|c|c|c|}
\hline & Capacity (kg/hr) & Efficiency \\
\hline \multicolumn{3}{|c|}{ Speed(rpm) } \\
\hline & $260.45^{\mathrm{b}}$ & $95.32^{\mathrm{a}}$ \\
\hline & $596.34^{\mathrm{a}}$ & $90.51^{\mathrm{a}}$ \\
\hline & $613^{\mathrm{a}}$ & $91.11^{\mathrm{a}}$ \\
\hline \multicolumn{3}{|c|}{ Mass(kg) } \\
\hline 1 & $370.03^{c}$ & $92.83^{\mathrm{ab}}$ \\
\hline 2 & $499.82^{b}$ & $95.35^{\mathrm{a}}$ \\
\hline 3 & $592.11^{\mathrm{a}}$ & $88.76^{\mathrm{b}}$ \\
\hline
\end{tabular}

Table 3: Analysis of variance for machine speed and cassava mash mass

\begin{tabular}{llll}
\hline Source of Variation & Df & Capacity (kg/hr) mean Square & Efficiency (\%) mean square \\
\hline Spread & 2 & $237510.58^{* * *}$ & $63.04^{\mathrm{NS}}$ \\
Mass & 2 & $69175.68^{* * *}$ & $113.84^{\mathrm{NS}}$ \\
Speed \& Mass & 4 & $48441.78^{* * *}$ & 68.50 \\
Error & 9 & 3517.35 & 28.71 \\
Total & 18 & & \\
Corrected Total & 17 & & \\
\hline
\end{tabular}

*** Significant $0.001 \%$.

Table 4: Cassava Mash to Chaff Ratio

\begin{tabular}{llll}
\hline $\begin{array}{l}\text { Initial mass } \\
\left(\mathbf{m}_{\mathbf{i}}\right) \mathbf{K g}\end{array}$ & $\begin{array}{l}\text { Mass of sieved } \\
\left(\mathbf{m}_{\mathbf{s}}\right) \mathbf{K g}\end{array}$ & $\begin{array}{l}\text { Mass of chaff } \\
\left(\mathbf{m}_{\mathbf{c}}\right) \mathbf{K g}\end{array}$ & $\begin{array}{l}\text { Ratio } \\
\mathbf{M}_{\mathbf{i}} / \mathbf{m}_{\mathbf{c}}\end{array}$ \\
\hline 1 & 0.88 & 0.12 & $8.33: 1$ \\
1 & 0.94 & 0.10 & $10: 1$ \\
1 & 0.90 & 0.12 & $8.33: 1$ \\
& & Average & $8.89: 1$ \\
\hline
\end{tabular}

The machine sifting efficiency trend is in agreement with that of Agbetoye and Oyedele (2007). Increase in machine speed increased sifting capacity but not the efficiency. Also, increase in machine loading decreased the sifting efficiency in accordance with Adejumo and Ola (2010). The reduction in sifting efficiency at load beyond $2 \mathrm{~kg}$ may be done to the fact that the particular mass on the sieve results to clogging of the sieve aperture while at high speed. The ratio of grated cassava mesh to sieved chaff is as presented in Table 4 . The ratio is necessary in assessing the performance of cassava grater for gari production. Cassava mesh - chaff ratio less 8.89 is not recommendable.

The machine is simple to operate and maintain with less complex parts. These enhance its adoption and utilization by low and medium level scale farmers for gari production.

\section{Conclusion}

A motor-operated gari sifting machine was developed and evaluated. The optimum performance of the sifter was at machine speed of $260 \mathrm{rpm}$ and loading mass of $2 \mathrm{~kg}$ per batch. The machine had highest sieving capacity and efficiency of $894.78 \mathrm{~kg} / \mathrm{hr}$ and $99.18 \%$ respectively. Though the sifter can be operated manually, using electric motor or ic engine is preferred for better performance. The machine could be adopted to handle other low bulk density materials such as flour, grain, sand and other powdery products.

\section{References}

Adejumo B. A. and Ola F. A. (2010). Development of a Combine Gari Post Grinder Sifting Machine. Journal of Agricultural Engineering and Technology. Vol. 18 No2. Pp. 77 -86.

Agbetoye L. A. S. and Oyedele D. A. (2007). Development of a Dual Powered Gari Sifter. Journal of Agricultural Engineering and Technology. Vol. 15. Pp. $32-39$.

IITA, (2005). The uses of cassava. Published by the integrated cassava project of the International Institute of Tropical Agriculture, Ibadan. Nigeria pp 87,95, 98.

Jackson B. A., Oladipo N. O., Adebija J. A. Farounbi A. J. and Oje K. (2011). Effect of operating speed on the sifting efficiency of a Dewatered Cassava Mash Sifter. Proceedings of Nigerian Institute of Agricultural Engineering. Vol. 32. Pp. $492-500$.

Samaila O. A., Ogunjirin O. A. and Olowonibi M. M. (2010). Development and Evaluation of Motorized Cassava Mash Sifter. Journal of Agricultural Engineering and Technology . Vol. 18. No. 2. Pp. 46 - 54. 